\title{
Lodging-Resistance Breeding of Platycodon grandiflorus Using Distant Hybridization
}

\author{
Yan Ma*, Yan Lin, Huali Zhang, Fang Liang, Liping Sun, Maoliang Wang, Haibo Xin \\ Beijing Institute of Landscape and Architecture, Beijing Key Laboratory of Green Plants Breeding, Beijing, China \\ Email: "mayanrong60@163.com
}

Received 30 September 2015; accepted 12 November 2015; published 16 November 2015

Copyright (C) 2015 by authors and Scientific Research Publishing Inc.

This work is licensed under the Creative Commons Attribution International License (CC BY).

http://creativecommons.org/licenses/by/4.0/

(c) (i) Open Access

\section{Abstract}

The distant hybridization was used in lodging-resistance breeding of Platycodon grandiflorus. The parents were Platycodon grandiflorus $(+)$ ) and Campanula medium ( $\left.{ }^{\lambda}\right)$. 187 seeds of $F_{1}$ were harvested by using the inter-generic hybridization in 2009 and 2010, 2 repeat, and 88 normal plants were obtained. The characteristics of leaves, stems and branches were the same as female for $F_{1}$ generation, $F_{2}$ generation, backcross generation and $S_{1}$ generation, and there were some different characteristics with female which were flower colors, branching habit and plant height. A lodging-resistance plant was selected in $F_{1}$, which was about $75 \mathrm{~cm}$ high, deep pink flower color and developed lateral branches. The DNA groups of each generation were separated by $1 \%$ agarose gel electrophoresis and there were not significant differences. Among the each generation many flower colors and forms were obtained.

\section{Keywords}

Lodging-Resistance Breeding, Platycodon grandiflorus, Campanula medium, Distant Hybridization

\section{Introduction}

Platycodon grandiflorum is a perennial flower, belonging to the family of Campanulaceae and genus of Platycodon. Chromosome base $2 \mathrm{n}=18$. Platycodon grandiflorum is about $80-120 \mathrm{~cm}$ high, leaves are alternate or 3 verticillate; flowers are solitary or several flowers in racemes; flower corolla is campanulate form with 5-lobed. Flowers' colors are usually blue, white and light pink. Flowering period is from June to October in each year. Platycodon grandiflorum was introduced in Beijing from Tianjin Institute of Landscape and Gardening in 2004. For a perennial flower it has a lot of excellent characters, such as: a long flowering period, more number of

*Corresponding author.

How to cite this paper: Ma, Y., Lin, Y., Zhang, H.L., Liang, F., Sun, L.P., Wang, M.L. and Xin, H.B. (2015) Lodging-Resistance Breeding of Platycodon grandiflorus Using Distant Hybridization. American Journal of Plant Sciences, 6, $2844-2849$. 
flowers, drought tolerance, cold tolerance, barren tolerance, little pests and diseases, and easy cultivation. So it could be used in the garden, sometimes as cut flowers or potted flowers. But it is easy lodging which has limited the application in landscape. In this research the breeding objective is lodging-resistance.

Campanula medium is biennial flowers, belonging to the family of Campanulaceae and genus of Campanula. Chromosome base $2 \mathrm{n}=34$. Campanula medium is about $70-80 \mathrm{~cm}$ high, raceme in apex, campanulate corolla. Flowers' colors are usually blue, white and pink. Campanula medium was introduced from Dongsheng Seed Co. Ltd. in 2008.

The bud mutations have been found in Platycodon grandiflorum which were the double-color flowers, and the petal numbers more or less than the normal, the double petal flower, and etc. Those characteristic might be induced to generate new variations. The forms of stigma, style, anther and filament of Platycodon grandiflorum and Campanula medium are similar, and the breeding goal is lodging-resistance of Platycodon grandiflorum, so Platycodon grandiflorum is chosen as female parent and Campanula medium as male parent. In cross breeding, the influence of female parent on hybrid offspring is often stronger than the male parent [1].

In this research, the inter-generic hybridization between Platycodon grandiflorum (i) and Campanula medium $\left(\delta^{\Uparrow}\right.$ ) has been used in the lodging-resistance breeding and many new characteristics have been obtained in $\mathrm{F}_{1}$ generation, such as the bright colors, dwarf form, developed lateral branches, lodging-resistance and etc. The superior individual plant was selected from $F_{1}$ generation, which was used to self-copulation and the characters of $S_{1}$ generation were better than those of $F_{1}$. Using this method the new varieties of Platycodon grandiflorum that are suitable for horticultural plant could be obtained.

\section{Materials and Methods}

\subsection{Materials}

Combined parents were listed in Table 1.

\subsection{Steps and Methods}

\subsubsection{Artificial Pollination Steps}

1) The stamens of Platycodon grandiflorum were castrated before anther dehiscence, and the petals were not removed.

2) The castrated female flowers were set on the anti-powder bag.

3) When the castrated female flowers were opening, the anti-powder bag was removed, and the stigma was pollinated with pollen of Campanula medium, and then the bag was recover.

4) The anti-powder bag was taken off at the stigma drying.

5) The fruits were harvested after the seeds were ripe.

6) The seeds were cleaned and numbered.

\subsubsection{Inter-Generic Hybridization, Hybridization, Self-Copulation and Backcross Breeding}

The inter-generic hybridization tests were carried out between Platycodon grandiflorum ( $\$$ ) and Campanula medium $\left({ }^{\top}\right)$ from 2009 to 2010. The stigma was pollinated two times on the day and the next day respectively. The objective plant of $\mathrm{F}_{1}$ generation was selected to be backcrossed with Campanula medium in July 13, 2011, one time pollinated, which was of new color, dwarf form and lodging-resistance. The objective plant of $F_{1}$ generation was used to self-copulation as well which was covered with anti-powder net for free pollination in June

Table 1. Parents combination.

\begin{tabular}{|c|c|c|c|}
\hline Materials & Female $(2 \mathrm{n}=18,+9)$ & Male $\left(2 n=34, \delta^{\pi}\right)$ & Generation \\
\hline Generic cross & Platycodon grandiflorum & Campanula medium & $\mathrm{F}_{1}$ \\
\hline Backcross & $\mathrm{F}_{1}$ & Campanula medium & Backcross generation \\
\hline Self-copulation & $\mathrm{F}_{1}$ & & $\mathrm{~S}_{1}$ \\
\hline $\mathrm{F}_{1}$ Group & $\mathrm{F}_{1}$ & $\mathrm{~F}_{1}$ & $\mathrm{~F}_{2}$ \\
\hline
\end{tabular}


14, 2012. The $F_{1}$ group was pollinated openly to obtain $F_{2}$ in 2010. The pollination date, times, and flowers number were listed in Table 2, in Table 2 the codes were set: Platycodon grandiflorum [PJ, o], Campanula medium [CM, $\left.{ }^{\top}\right]$, and the $\mathrm{F}_{1}$ was the selected objective plant from $\mathrm{F}_{1}$ group.

\subsubsection{Cultivation and Characteristics Investigation for $F_{1}, F_{2}, S_{1}$ and Backcross Generation}

The seeds of $F_{1}, F_{2}, S_{1}$ and backcross generation were sown in plug trays in green houses in winter. Survival seedlings were transferred into pots and cultured as container seedlings, which would be planted in field in next spring. From 2010 to 2015, the characteristics of $F_{1}, F_{2}, S_{1}$ and backcross generation were investigated after planting which were the lodging-resistance, plant height, flower colors, branches number, lateral branch number and flower number. Comparison analyses between samples were tested by One-Way ANOVA method.

\subsubsection{To Separate the DNA Groups of Different Generations}

The DNA groups were extracted from $\mathrm{F}_{1}, \mathrm{~F}_{2}, \mathrm{~S}_{1}$, backcross generation and parents, using the Plant Genomic DNA Kit which was produced by Tiangen Biotech (Beijing) CO., Ltd.

The PCR technique was used to extend the DNA group, the modified CTAB method was used to extract DNA for RAPD amplification reaction. PCR system: the total volume of basic reaction system were $25 \mu \mathrm{L}$, which include: $10 \times$ PCR buffer $2.5 \mu \mathrm{L}, 25 \mathrm{mmol} \cdot \mathrm{L}^{-1} \mathrm{MgCl}_{2} 2.0 \mu \mathrm{L}, 2.5 \mathrm{mmol} \cdot \mathrm{L}^{-1} \mathrm{dNTP} 2.0 \mu \mathrm{L}, 2.5 \mathrm{U} \cdot \mathrm{L}^{-1}$ Taq enzyme $0.5 \mu \mathrm{L}, 5 \mu \mathrm{mol} \cdot \mathrm{L}^{-1}$ primer $4.0 \mu \mathrm{L}$, template DNA $10 \mathrm{ng}$, sterile ultra pure water up to $25 \mu \mathrm{L}$. The primer name is S12 and the sequence is 5'-CCTTGACGCA-3' [2].

PCR reaction program: $94^{\circ} \mathrm{C} 4 \mathrm{~min}, 94^{\circ} \mathrm{C} 30 \mathrm{~s}, 35^{\circ} \mathrm{C} 1 \mathrm{~min}, 72^{\circ} \mathrm{C} 2 \mathrm{~min}, 45$ cycles, $72^{\circ} \mathrm{C}, 10 \mathrm{~min}$. The DNA groups were separated by $1 \%$ agarose gel electrophoresis.

\section{Results and Discussion}

\subsection{Inter-Generic Hybridization, Self-Copulation and Backcrossed Analysis}

The investigation of inter-generic hybridization, self-copulation and backcross were performed from 2009 to 2015. The survey results were listed in Table 3, as Table 3 shown, in inter-generic hybridization 80 flowers were pollinated, 6 seed settings and 187 seeds were harvested, 88 seedlings were obtained, the average seed setting rate was $7.6 \%$, and the average seedling rate was $50.4 \%$. In backcross 15 flowers were pollinated, 15 seed settings and 457 seeds were harvested, 316 seedlings were obtained, the average seed setting rate was $86.7 \%$, and the average seedling rate was $69.1 \%$. In self-copulation 16 seed settings and 530 seeds were harvested, 348 seedlings were obtained, the average seed setting rate was $2.1 \%$, and the average seedling rate was $65.7 \%$.

Table 2. The pollination date, times, and flowers number.

\begin{tabular}{|c|c|c|c|}
\hline Parents & Emasculation (y-m-d) & Pollination date (y-m-d) & Pollination No. \\
\hline $\mathrm{PJ}(+) \times \mathrm{CM}\left({ }^{\lambda}\right)$ & 2009-6-16 & 2009-6-16, 17 & 24 \\
\hline $\mathrm{PJ}(+) \times \mathrm{CM}(\overbrace{}^{\Uparrow})$ & 2009-7-1 & 2009-7-2, 3 & 25 \\
\hline $\mathrm{PJ}(+) \times \mathrm{CM}\left({ }^{\lambda}\right)$ & $2010-6-24$ & 2010-6-24, 28 & 31 \\
\hline $\mathrm{F}_{1}(+) \times \mathrm{CM}(\overbrace{}^{\widehat{*}})$ & 2011-7-13 & 2011-7-14 & 15 \\
\hline $\mathrm{F}_{1}\left(\right.$ (†) $\times \mathrm{F}_{1}\left({ }^{\Uparrow}\right)$ & 2012-6-14 & $2012-6-14$ & 779 \\
\hline
\end{tabular}

Table 3. Investigation results of hybridization, backcross and self-copulation.

\begin{tabular}{|c|c|c|c|c|c|c|}
\hline Parents & Pollination No. & Seed setting No. & Seeds No. & Plants No. & Seed setting rate (\%) & Seedling rate (\%) \\
\hline $\mathrm{PJ}($ ( $) \times \mathrm{CM}(\widehat{\jmath})$ & 80 & 6 & 187 & 88 & 7.6 & 50.4 \\
\hline $\mathrm{F}_{1}(\mathrm{q}) \times \mathrm{CM}(\overbrace{}^{\lambda})$ & 15 & 13 & 457 & 316 & 86.7 & 69.1 \\
\hline $\mathrm{F}_{1}(\mathrm{O}) \times \mathrm{F}_{1}\left(\mathrm{O}^{\lambda}\right)$ & 779 & 16 & 530 & 348 & 2.1 & 65.7 \\
\hline
\end{tabular}


In this study, compare of the seed seedling rate: self-copulation < inter-generic hybridization < backcross, the reason might be: the self-copulation was the self pollination that the different growth period of pistil and stamen in the same flower caused the low seed setting rate [3]; inter-generic hybridization is of the far phylogenetic relationship, the isolation mechanism were produced during the evolutionary process, so the seed setting rate is very low [4]; backcross was the highest in this test, that backcross method has been proved to be an effective way to solve the problems of distant hybridization which were the hybrid sterility and the isolation from generation to generation so long [5]. In addition, the inter-generic hybridization was repeated 3 times, and each time the living seeds were obtained which could grow into seeding, the further research is needed in the future to prove the reason.

\subsection{Characteristics Investigation of $\mathrm{F}_{1}, \mathrm{~S}_{1}$ and Backcross Generation}

In this study the objective plant was selected in $\mathrm{F}_{1}$ group which was the survey and test sample, because of the deep pink flower color, dwarf plant form, more bough number, lateral branching habit, and especially lodging-resistance. The characteristics of the $\mathrm{F}_{1}, \mathrm{~S}_{1}$ and backcross generation were investigated that the results were listed in Table 4, as the Table 4 shown: the plant height was: $\mathrm{S}_{1}<\mathrm{F}_{1}<$ backcross generation $<$ female, there was significant difference between each generation and female; the bough number was: $S_{1}>F_{1}>$ backcross generation $>$ female, there was significant difference between $S_{1}$ and $F_{1}$ with backcross generation and female; the lateral branches number was: $S_{1}>F_{1}>$ backcross generation, there was significant difference between $S_{1}$ and $F_{1}$ with backcross generation; flower number of each branch was: $S_{1}>F_{1}>$ backcross generation $>$ female, there was significant difference between each generation and female. Especially the selected $\mathrm{S}_{1}$ was of the developed characteristics. By artificial self-copulation and selection, not only can make the gene homozygous, but also make the good character to be accumulated and strengthened [5].

The reason of lodging resistance might be the developed lateral branch which make the plant gravity center lowing. The increasing flower number of each branch might be the developed lateral branch too. Varieties with moderate plant height, branch point, plant height and number of branches, lower gravity center of plant, compact plant architecture possess high lodging resistance [6].

The objective plant pictures of $F_{1}, S_{1}$, backcross generation and parents were shown in Figure 1 . The survey results and pictures were shown that the flower color of each generation were different from their parents, but the leaves, stems and flower forms were same with the female's (Figure 1) that might be in tow possible, one is the apomixes phenomenon anther is the distant hybridization. The genetic material of apomictic progeny is just as male or female, and the character is just as male or female too [7]. Some people thought that the distant hybrid has not changed necessarily in chromosome number and forms, this problem should be researched in the future [7].

\subsection{The Electrophoresis Separation of DNA Groups Comparison}

In this test the DNA groups $F_{1}, F_{2}, S_{1}$, backcross generation and parents were separated by $1 \%$ agarose gel electrophoresis. The separated results were shown in Figure 2, as the Figure 2 shown that the separated DNA groups of each plant were represented by each amplified band, 1 was marker, 2 was male, 3 was female, 4 to 15 were $F_{1}, 16$ to 22 were $F_{2}, 23$ to 27 were backcross generation and 28 to 33 were $S_{1}$ (Figure 2). Compared with the amplification bands of $F_{1}, F_{2}, S_{1}$, backcross generation and female there were no difference among them.

Table 4. Comparative analysis of characteristics to different generation (Average for many years).

\begin{tabular}{cccccc}
\hline Generation & Color & High $(\mathrm{cm})$ & Bough No. & Lateral branch No. & Flower No. of each branch \\
\hline 0 & White, Purple & $78.3 \pm 4.41$ & $1 \pm 0.0$ & 0 & $28.0 \pm 1.155$ \\
+ & White, Purple & $120.0 \pm 5.77 \mathrm{a}$ & $8.0 \pm 0.58 \mathrm{~b}$ & 0 & $22.3 \pm 0.33 \mathrm{c}$ \\
$\mathrm{F}_{1}$ & Deep Pink & $75.0 \pm 2.89 \mathrm{~b}$ & $14.3 \pm 0.88 \mathrm{a}$ & $12.0 \pm 0.58 \mathrm{a}$ & $63.0 \pm 0.58 \mathrm{a}$ \\
$\mathrm{S}_{1}$ & Deep Pink & $70 \pm 2.89 \mathrm{~b}$ & $15.67 \pm 0.88 \mathrm{a}$ & $12.33 \pm 1.20 \mathrm{a}$ & $65.00 \pm 1.15 \mathrm{a}$ \\
Backcross & Deep Pink & $80 \pm 2.00 \mathrm{~b}$ & $10.0 \pm 1.00 \mathrm{~b}$ & $8.5 \pm 0.50 \mathrm{~b}$ & $47.0 \pm 1.00 \mathrm{~b}$ \\
\hline
\end{tabular}

Note: Values are mean $\pm \mathrm{SE}$, different letters within the same column indicate mean values statistically different at $\mathrm{p}<0.05$ as determined by LSD test. 

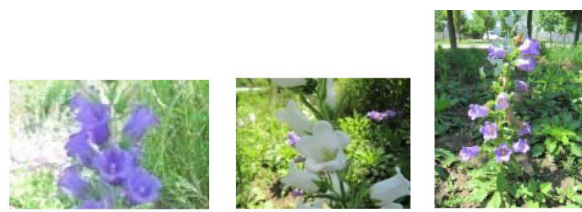

1.Male
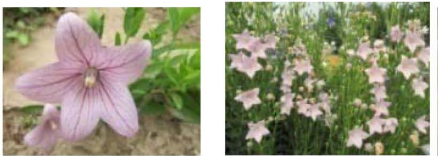

$3 . \mathrm{F}_{1}$

$\mathrm{F}_{1}$

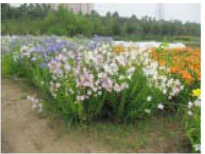

$\mathrm{F}_{1}$
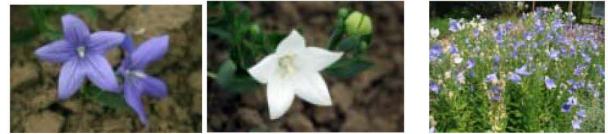

2.Female
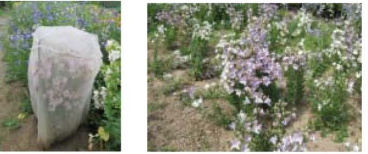

(self-copulation) $\mathrm{S}_{1}$

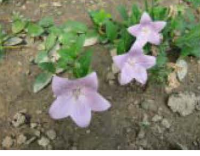

backcross generation

Figure 1. The pictures of the objective plant of $\mathrm{F}_{1}, \mathrm{~S}_{1}$, backcross generation and parents.
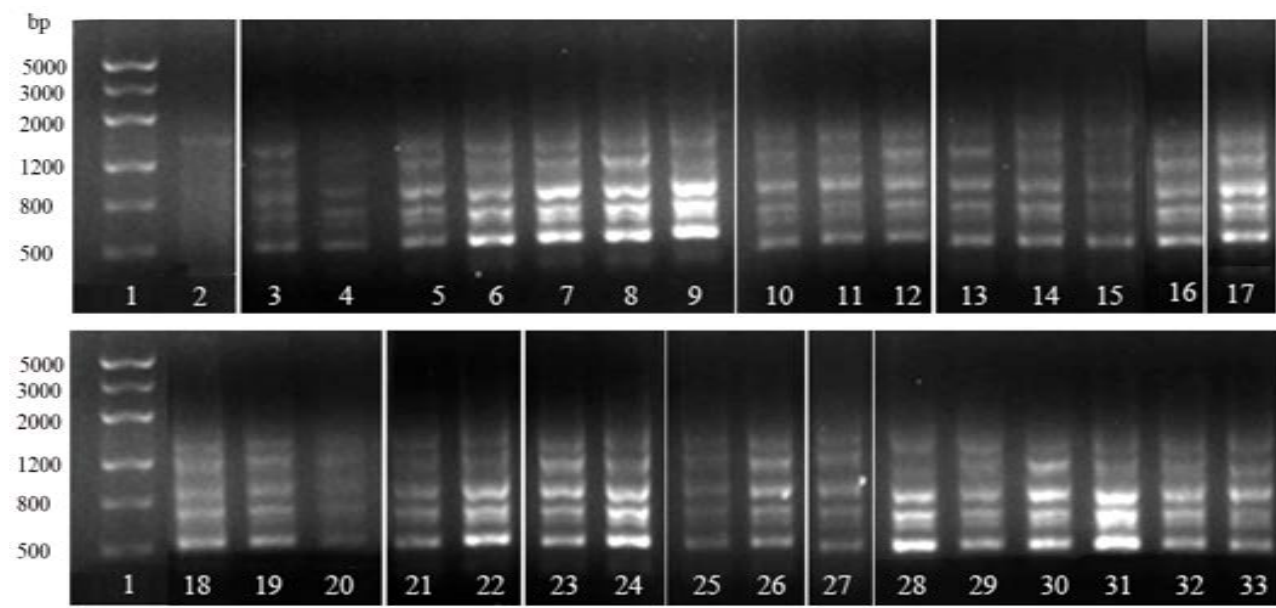

Figure 2. Separation of DNA groups. Marker: 1, Male: 2, Female: 3, $F_{1}: 4$ to 15, $F_{2}: 16$ to 22, Backcross generation: 23 to $27 ; \mathrm{S}_{1}: 28$ to 33 .

In this study, the separated DNA groups have no significant difference and the possible reasons are: the screened primers were not suitable for those DNA groups (10 primers were selected for the experiment, and S12 was the best one); some research shown a multiplex PCR method was developed by which specific fragments with different length in a DNA sample mixture isolated from six transgenic maize could be amplified simultaneously in one PCR reaction, meanwhile, one fragment of maize endogenous reference gene (zein) could also be detected [8]; the concentration of agarose gel was not thick enough to make the amplified bands clearly; which was a apomixes phenomenon, apomixes is a phenomenon that the plants produce seeds directly and there is no fusion process of sperm and ovum [7], parthenocarpy is a kind of apomixes that the oocyte is not fertilized, but the fruit can be normally developed under the stimulation of pollen [9]. In the future more studies will be conducted.

\section{Inquire into Other Findings}

In this study many of new flower colors and flower forms were obtained from $F_{1}$ and $F_{2}$, which were shown in Figure 3. The colors and forms of flower will enrich the variety of Platycodon grandiflorum, so the research object should be sustainably developed in the future.

\section{Conclusion}

The inter-generic hybridization was used between Platycodon grandiflorum and Campanula medium, and lodging-resistance plant has been obtained from $\mathrm{F}_{1}$ that the morphological characteristics were similar with female, 


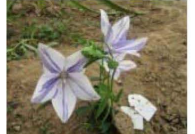

1. $\mathrm{F}_{1}$

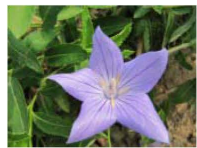

7. $\mathrm{F}_{1}$

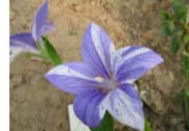

2. $\mathrm{F}_{1}$

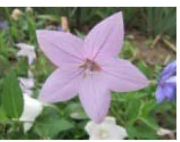

8. $\mathrm{F}_{1}$

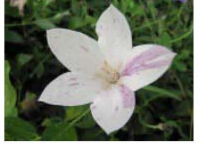

3. $\mathrm{F}_{1}$

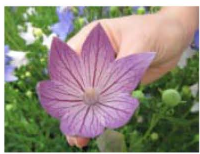

9. $\mathrm{F}_{1}$

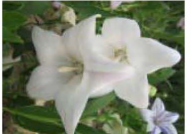

4. $\mathrm{F}_{1}$

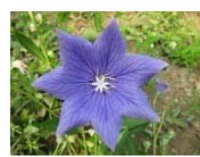

10. $\mathrm{F}_{2}$

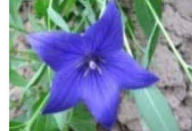

5. $\mathrm{F}_{1}$

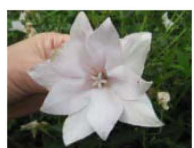

11. $\mathrm{F}_{2}$

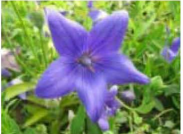

6. $F_{1}$

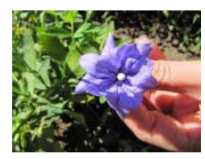

12. $\mathrm{F}_{2}$

Figure 3. The rich flower colors and forms.

as well as other offspring. The DNA groups of each generation and parents were separated by $1 \%$ agarose gel electrophoresis, but the results hadn't been got. A lot of flowers' colors and forms have been obtained from the offspring.

\section{References}

[1] Cheng, J.S. and Liu, Q.L. (2000) Garden Plant Genetics and Breeding. China Forestry Press, Beijing.

[2] Wang, B.N., Zhang, X., Chen, J.M. and Song, J.Y. (2011) Optimization of RAPD Reaction System on Wild Cymbidium Faber in Qinling Mountain. Journal of Northwest A\&D University(Natural Science Edition), 39, 87-84.

[3] Wu, J.R., Yan, Y.Z., Wu, S.Q., Zhang, Z. and Li, M.S. (2005) The Causes and Settling Method of Low Seed Setting Rate of Platycodon grandiflorum by Self-Pollination. Journal of Agricultural Science Yanbian University, 27, 56-60.

[4] Liu, W.D., Zhu, S.N. and Cui Q.X. (2005) Horticultural Crops Genetics and Breeding. China Agricultural Science and Technology Press, Beijing.

[5] Yang, G.S. and Yuan, H.Y. (2009) Principle of Crop Breeding. Science Press, Beijing.

[6] Chen, X.J., Qi, C.K., Pu, H.M., Zhang, J.F., Gao, J.Q. and Fu, S.Z. (2007) Evaluation of Lodging Resistance in Rapeseed (Brassica napus L. ) and Relationship between Plant Architecture and Lodging Resistance. Chinese Journal of Oil Crop Sciences, 29, 54-57.

[7] Liu, Z.K., Luo, H., et al. (2010) Modern Plant Breeding. Science Press, Beijing.

[8] Jin, W.J., Hao, Y., Cheng, H.M., Lu, X.B., Peng, Y.F. and Jia, S.R. (2005) Specific Detection of Alien DNA Sequences in Six Transgenic Maize by Using Multiplex PCR Method. Journal of Agricultural Biotechnology, 13, 562-567.

[9] Hu, H.W. (2010) Crop Genetics and Breeding. Chemical Industry Press, Beijing. 